\title{
Retraction Note to: Triptolide (TPL) improves locomotor function recovery in rats and reduces inflammation after spinal cord injury
}

\author{
Bing Wang $^{1} \cdot$ Chen Chen ${ }^{1} \cdot$ Jing-Tao Zhang ${ }^{1} \cdot$ Ruo-Xian Song ${ }^{1} \cdot$ Xiu-Chun Yu $^{1}$
}

Published online: 6 February 2017

(C) Springer-Verlag Italia 2017

\section{Retraction Note to: Neurol Sci (2015) 36:701-705}

\section{DOI 10.1007/s10072-014-2001-4}

Following an internal investigation, this article is retracted at the author's request and in consent with the Editor-inChief due to similarities in Figures 1, 4, 6 in Neurological Sciences, and Figures 1, 6 and 4 respectively in the paper by Chong Xun, et al. "Study of Effect of Salvianolic Acid B on Motor Function Recovery in Rats with Spinal Cord Injury", published in BioMed Research International, Volume 2014, Article ID 931850.

The online version of the original article can be found under doi:10.1007/s10072-014-2001-4.

Xiu-Chun Yu

xiuchun531@hotmail.com

1 Department of Orthopaedic, The General Hospital of Jinan Military Commanding Region, No. 25 Shifan Road, Tianqiao District, Jinan 250031, Shandong, China 